\section{Silva Coutinho: uma trajetória profissional e sua contribuição às coleções geológicas do Museu Nacional*}

\section{Silva Coutinho: his career and his contributions to the geological collections of the Museu Nacional in Rio de Janeiro}

\author{
Marina Jardim e Silva \\ Mestranda do Programa de Pós-graduação em \\ História/Universidade Federal do \\ Estado do Rio de Janeiro. \\ Av. Pasteur, 458 \\ 22290-240 - Rio de Janeiro - RJ - Brasil \\ marina.jardim@yahoo.com.br
}

\begin{abstract}
Antonio Carlos Sequeira Fernandes
Professor do Departamento de Geologia e Paleontologia (DGP) do Museu Nacional (MN)/Universidade Federal do Rio de Janeiro (UFRJ). Quinta da Boa Vista, s.n. 20940-040 - Rio de Janeiro - RJ - Brasil fernande@acd.ufrj.br
\end{abstract}

\section{Vera Maria Medina da Fonseca \\ Professora do DGP/MN/UFRJ. Quinta da Boa Vista, s.n. 20940-040 - Rio de Janeiro - RJ - Brasil \\ vmmedinafonseca@gmail.com}

Recebido para publicação em abril de 2011. Aprovado para publicação em agosto de 2011.
SILVA, Marina Jardim e; FERNANDES, Antonio Carlos Sequeira; FONSECA, Vera Maria Medina da. Silva Coutinho: uma trajetória profissional e sua contribuição às coleções geológicas do Museu Nacional. História, Ciências, Saúde - Manguinhos, Rio de Janeiro, v.20, n.2, abr.-jun. 2013, p.457-479.

\section{Resumo}

A trajetória profissional de João Martins da Silva Coutinho relaciona-se à história do Museu Nacional (Rio de Janeiro), para cujas coleções, principalmente geológicas, ele contribuiu com informações científicas e remessa de material. No cenário científico brasileiro, participou de grandes comissões de caráter exploratório na segunda metade do século XIX, especialmente na Amazônia e no Nordeste. Coletou e enviou amostras para análise no Museu Nacional, estabelecendo profunda relação com a instituição e seus funcionários. Apresentam-se essas contribuições por meio da análise de documentos e da recuperação das coleções geológicas por ele remetidas e ainda presentes no acervo da instituição.

Palavras-chave: João Martins da Silva Coutinho (1830-1889); Museu Nacional (Rio de Janeiro); coleções científicas; geologia; Brasil.

\section{Abstract}

The career of João Martins da Silva Coutinho is linked to the history of the Museu Nacional in Rio de Janeiro to whose collections (especially geological) he contributed scientific information and material. On the Brazilian scientific stage, Silva Coutinho took part in major exploratory commissions in the latter half of the nineteenth century, mainly in the Amazon and in the Northeast. He collected and sent samples to the Museu Nacional for analysis, establishing deep ties with the institution and its staff. The article presents his contributions through an analysis of these documents and an examination of the geological collections that he sent to the institution and that remain part of its holdings.

Keywords: João Martins da Silva Coutinho (1830-1889); Museu Nacional (Rio de Janeiro); scientific collections; geology; Brazil. 
E ntre 1875 e 1876, o engenheiro João Martins da Silva Coutinho (1830-1889) ocupou o cargo de diretor da Terceira Seção do Museu Nacional, e, apesar da curta permanência, sua contribuição à instituição é relevante, pois nas décadas anteriores e posteriores, fez doação do material geológico que coletou nas diversas expedições das quais participou.

Sua atuação profissional foi marcada pelo engajamento em diversas comissões constituídas no século XIX, como a Comissão Científica de Exploração, que funcionou entre 1859 e 1861, a Expedição Thayer realizada entre 1865 e 1866, e, por três vezes, representou o Brasil em exposições universais. Além disso, Silva Coutinho atuou na definição do território nacional através da demarcação das fronteiras e da exploração de áreas e rios ainda pouco conhecidos da Amazônia. Vale salientar que o país ainda estava em processo de desenhar seu território e ocupar áreas mais remotas, sobre as quais o governo detinha pouco controle. Seu nome também está ligado às ferrovias, pois foi responsável por estudos e pela implantação de longos trechos de estradas de ferro, visando ao desenvolvimento econômico e à integração nacional. Silva Coutinho percorreu o espaço urbano e rural, a Corte e diversas províncias, além de ter estado em contato com os índios que então, muitas vezes de forma idealizada, eram um tema caro à literatura.

A documentação relacionada a Silva Coutinho presente em instituições arquivísticas do Rio de Janeiro esclarece suas atividades como engenheiro civil e militar, mas de forma geral silencia sobre sua vida familiar, com exceção das informações relacionadas a seu inventário e a um processo judicial em que tentou manter sob seus auspícios a escrava Magdalena, cujos documentos se encontram depositados no Arquivo Nacional (Inventário..., 1889). No estado do Pará, o Museu Paraense Emilio Goeldi reuniu rico conjunto de fontes diretamente vinculadas a ele, e o inventário analítico produzido pela instituição oferece diagnóstico equivalente: há pouca documentação pessoal ou anterior a sua carreira.

Os aspectos profissionais da trajetória de João Martins da Silva Coutinho são abordados neste trabalho com o objetivo de analisar sua contribuição ao Museu Nacional, o que inclui sua participação em diversos eventos de relevo para a história científica imperial. Das doações às coleções do museu observa-se ainda quais e quantas amostras selecionadas por ele em suas andanças pelo país encontram-se preservadas ainda hoje - depois de mais de um século -, ressaltando seu valor como constituinte do patrimônio histórico e científico.

\section{O engenheiro militar: início e consolidação profissional}

A atuação profissional de João Martins da Silva Coutinho esteve inscrita no recorte temporal referente à governança de dom Pedro II, iniciada com a maioridade, em 1841. Silva Coutinho nasceu no município de São João da Barra, no Rio de Janeiro, em 1 o de maio de 1830 e faleceu em Paris em 11 de outubro de 1889. Era filho do militar, escritor e político Fernando José Martins da Silva e de Maria Joaquina Barreto de Faria, ambos pertencentes a respeitadas famílias. Seus dois matrimônios não destoaram do pertencimento à chamada boa sociedade: sua primeira esposa foi Maria do Carmo Marques Lisboa, filha do marechal Henrique Marques de Lisboa e sobrinha do marquês de Tamandaré. Com ela teve dois filhos: Francisca Marques Lisboa Coutinho (1862-1933), que se casou com Manuel Buarque de Macedo, e Fernando Lisboa Coutinho (1864-1939). Silva Coutinho contraiu o segundo 
matrimônio com Maria Joaquina Ewbank da Câmara (1845-1923), também de renomada família, com a qual permaneceu até a morte. Dessa união nasceram os filhos Luiz da Câmara Coutinho, João Martins da Câmara Coutinho e Jorge da Câmara Coutinho (Inventário..., 1889; Brasil Genealógico, 1961; Holanda, 2007).

Sua formação deu-se na antiga Escola Militar, em que frequentou o curso de engenharia ${ }^{1}$, ocupando a posição de alferes-aluno. Criado em 1840, o posto de alferes-aluno era preenchido por aqueles que se destacassem nos estudos. Visando estimular os estudantes, garantia vencimento maior do que o dos outros, sem que fosse considerado hierarquicamente superior aos demais (Castro, 2004).

Concluído o curso e formado bacharel em matemática e ciências físicas entre os melhores alunos, Silva Coutinho seguiu carreira no Corpo de Engenheiros no Exército. Entre as atividades exercidas foi opositor interino de matemática e ciências físicas e naturais (Almanak..., 1859), opositor efetivo na mesma cadeira (Almanak..., 1860), repetidor (Almanak..., 1861) e professor de desenho na Escola Central. Permaneceu como militar até 1865 quando deu entrada no pedido de desligamento, deixando para trás sua patente de major à qual fora promovido por merecimento no mesmo ano (Documento..., 1865).

Como militar engenheiro, na década de 1850 foi adjunto do Observatório Astronômico

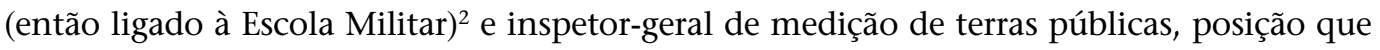
ocupou na província do Pará (Pasta..., s.d.). Nos últimos anos dessa década, Silva Coutinho atuou como geólogo adjunto ao lado do engenheiro Guilherme Shüch, barão de Capanema (1824-1908), na expedição da Comissão Científica de Exploração (também conhecida como Comissão das Borboletas, Comissão do Ceará ou Imperial Comissão Científica), realizada por iniciativa do Instituto Histórico e Geográfico Brasileiro (IHGB) para explorar as províncias do Norte e Nordeste, com início no Ceará (Kury, 2009a; Lopes, 1996, 2009). Fato curioso é que o relatório do Museu Nacional para o ano de 1857, assim como o Almanaque Laemmert de 1860, não apresentam seu nome entre os dos membros da Comissão, mas sim o de Miguel da Silva Coutinho (Almanak..., 1860). Apesar da existência dessas duas fontes (que derivam uma da outra), o engenheiro efetivamente participou das atividades.

A ideia de criar uma expedição de caráter nacional que percorresse o Norte e Nordeste foi proposta em sessão do IHGB de 30 de maio de 1856 e aprovada pelo governo imperial. Decidiuse por uma organização em cinco seções que deveriam explorar os locais percorridos, obter material para as coleções do Museu Nacional e redigir uma instrução por seção. Participaram da comissão científica membros das duas instituições: o médico e naturalista Francisco Freire Allemão de Cysneiros (1797-1874) e o botânico Manoel Freire Allemão (?-1863), seu sobrinho, na seção de botânica; o engenheiro Guilherme Schüch de Capanema e Silva Coutinho para cuidar dos assuntos geológicos e mineralógicos; Manoel Ferreira Lagos (1816-1871) e os irmãos naturalistas preparadores João Pedro Vila-Real e Lucas Antônio Vila-Real, na de zoologia; o primeiro-tenente e matemático Giacomo Raja Gabaglia (1826-?) na seção de astronomia e geografia, acompanhado de seis adjuntos; Antonio Gonçalves Dias (1823-1864) e seu adjunto, Francisco de Assis Azevedo Guimarães (?-1860), compondo a seção de etnografia e a narrativa da viagem; e o pintor José dos Reis Carvalho (c.1798/1800-c.1892), que seguiu como desenhista (Almanak..., 1860, supl., p.60-61; Braga, 1982; Kury, 2009b). Os chefes de cada seção eram sócios do IHGB, e Freire Allemão e Capanema diretores de seção do Museu 
Nacional, sendo que o primeiro tornar-se-ia também diretor-geral do museu anos depois, de 1866 até 1874 (Lopes, 1997). Além do Ceará, os naturalistas percorreram regiões do Piauí, Pernambuco, Paraíba e Rio Grande do Norte. Antonio Gonçalves Dias, um dos membros, após dar por finalizada sua participação no Ceará, passou pelo Maranhão e Pará, chegando a Manaus (Lopes, 1996, 2009; Kodama, 2009).

A despeito dos problemas financeiros, condições climáticas adversas, falta de apoio externo e dos atritos entre os membros e com as autoridades, a expedição contribuiu significativamente para o IHGB e o Museu Nacional. Este último recebeu expressiva quantidade de objetos para as seções de geologia e botânica, assim como instrumentos usados e livros que foram destinados à incorporação permanente. A comissão, embora inicialmente debatida pelos ministros na assembleia como assunto do IHGB, logo passou a ser relacionada ao museu.

Silva Coutinho desempenhou importante papel na Comissão Científica de Exploração, pois, como afirmou Margaret Lopes (2009, p.70), "na ausência do chefe da seção geológica, ... excursionou e coletou amostras e informações sobre minas pelos arredores de Fortaleza". Cerca de cinco meses antes de seu encerramento, em fevereiro de 1861, Silva Coutinho iniciou aquele que seria seu primeiro trabalho técnico em um rio da Amazônia. Realizou detalhado levantamento da planta do rio Purus a pedido do presidente da província do Amazonas, Manoel Clementino Carneiro da Cunha (1825-1890), além de produzir longo parecer sobre o rio e seus afluentes, em que defendeu a ideia de que a falta de conhecimento do rio Purus até então fazia com que não lhe fosse dada a devida importância. Sua navegação fácil e sem cachoeiras levou Silva Coutinho a afirmar que seria melhor navegável do que o rio Madeira. Até meados do século XIX, poucas foram as investidas visando ao reconhecimento do local, ocupado por diferentes grupos de índios e com pouca intervenção externa, como a de coletores de drogas do sertão. Na viagem estavam também, segundo Silva Coutinho (1865a) ${ }^{3}$, tripulantes, o prático Manuel Urbano, o coletor de plantas alemão Gustav Wallis (1830-1878) e um senhor chamado H. Strauss, cuja ocupação não é informada, contando ainda com ajuda de alguns índios. No mesmo ano, Silva Coutinho (1861) percorreu também o rio Madeira com o objetivo de examinar os edifícios públicos, apontar a melhor localidade no rio para estabelecer uma colônia nacional e propor os melhoramentos pertinentes.

Acompanhando o rio Purus, observou níveis de água, cheias e vazantes, correntes, cores das águas, épocas de chuva, terreno, descrevendo os afluentes e o que via nas margens. Os índios constituíam presença impossível de ser ignorada, e os relatórios oferecem um pouco de sua visão sobre o contato. Dedicou uma parte específica do trabalho às 18 tribos conhecidas, mas ao longo de todo o texto várias e interessantes são as observações sobre algumas delas e seus costumes. Havia ainda os grupos desconhecidos - muitos arredios e resistentes - com os quais não era possível a comunicação verbal, confirmando que o local era, até então, pouco explorado. Defendia como política para o local o envio de missionário para catequese, apresentando a moral, a religião, a civilidade e as virtudes do trabalho, sobretudo aos grupos que acreditava serem mais propensos às atividades na lavoura. A colonização, concluiu, devia ser acompanhada de educação indígena (Silva Coutinho, 1865a). Findo o trabalho no rio Purus, Silva Coutinho embarcou em expedição pelo rio Madeira acompanhado de Antonio José Rodrigues, homem que asseguraria a continuidade aos trabalhos no caso de sua impossibilidade. Em sensível estado de saúde e assustado por ameaça de "congestão 
cerebral" (Silva Coutinho, 1865b, p.A-Q-56), encarou uma viagem conturbada. O rio Madeira era conhecido por sua navegação tortuosa, e a tripulação que contava com mais 22 homens (entre índios e soldados) sofreu com a perda de mantimentos que com frequência caíam na água (Silva Coutinho, 1865b).

Em suas observações de viagem Silva Coutinho afirmou ter coletado amostras de granito. As cachoeiras até os Três Irmãos eram constituídas de granitos diferentes e, a partir daí, aparecia o micaxisto com vieiros de sílex, "alguns de grande possança, como na pederneira, onde se distingue perfeitamente o contato e o metamorfismo" (Silva Coutinho, 1865b, p.A-Q-59). Fez ainda anotações de latitude, meteorológicas e de temperaturas do ar, água, areia e pedras. Nos relatórios sobre os rios Purus e Madeira, ainda que de forma sutil, reclama da falta de instrumentos necessários, o que o impedira de cumprir objetivos conforme desejava, no primeiro relatório, para o levantamento da planta, no segundo, para determinação da longitude.

Mais uma vez prestou serviço ao governo da província do Amazonas, realizando o levantamento da planta da cidade e apresentando orçamento para seu melhoramento. Foi também presidente da exposição de produtos naturais e industriais da província (Doutor João..., 1906, p.VIII).

Em 1863, Silva Coutinho teve a primazia da localização dos depósitos de fósseis de invertebrados do Paleozoico na região do vale do Tapajós, na província do Pará (Rosado, 1998; Lopes, 1997). Em 1864, "por requisição do Ministério dos Negócios Estrangeiros" (Rosado, 1998, p.5), foi membro da comissão, com sede em Belém, cuja incumbência era firmar os limites de fronteira do Brasil com o Peru; nessa missão assumiu a chefia, substituindo o capitão-tenente José da Costa Azevedo (1823-1904), futuro barão de Ladário e ministro da Marinha em 1889 (Doutor João..., 1906, p.VIII). Em resumo, Silva Coutinho passou a maior parte da década de 1860 na Região Norte do país em comissões de engenheiros (Almanak..., 1862, 1863, 1864a, 1864b, 1865). Foi nessa ocasião que, em Manaus, estando casado desde 1862, nasceram seus dois primeiros filhos, Francisca e Fernando, e ele obteve uma promoção em sua carreira militar. Em Mato Grosso, o jornal A Imprensa de Cuiabá publicou o decreto de 18 de fevereiro de 1865, tratando de promoções militares, entre elas a de Silva Coutinho, a major por merecimento, e festejou em suas páginas a vitória dos brasileiros contra a invasão paraguaia ao Mato Grosso em meio à guerra. Cerca de ano e meio depois, entretanto, em 28 de setembro de 1866, Silva Coutinho demitiu-se do serviço militar (Doutor João..., 1906, p.VIII).

O historiador norte-americano Warren Dean (1932-1994) vinculou o nome de Silva Coutinho à história da borracha no Brasil, quando tratou da luta brasileira em torno desse produto fundamental para o país em termos de exportação (Dean, 1989). A borracha era obtida por extrativismo e, na segunda metade do século, começaram a soar as primeiras vozes a favor do plantio de árvores que a produzissem. Nesse sentido, Guilherme de Capanema apresentouse em 1856 na Sociedade Palestra Científica - associação "dedicada às ciências naturais e às ciências físicas e matemáticas" cujas reuniões ocorriam na Escola Central (Lopes, 1997, p.135) - em defesa do plantio da seringueira em substituição à retirada do látex, seguindo o exemplo dos holandeses, que adotaram a mudança de procedimento com a cinchona, planta da qual algumas espécies produzem o quinino. Anos depois, Silva Coutinho admitiu preocupação com o possível fim das árvores silvestres diante da ascendente demanda do mercado mundial e dos agressivos métodos de extração e sugeriu seu cultivo no Pará (e posteriormente em São 
Paulo). Diante da falta de interesse por sua sugestão, que não foi acatada, enviou sementes ao Museu Nacional que foram então plantadas. Silva Coutinho, que buscava a obtenção do produto de maneira racionalizada e com menor dano à natureza, deu ainda outro passo para a mudança na história da borracha. Quando compôs o júri da Exposição Universal de Paris em 1867, ele teria chamado a atenção de alguns europeus para o cultivo da borracha, que foi iniciado por impulso do geógrafo e explorador inglês sir Clements Robert Markham (1830-1916) no Royal Botanical Gardens de Kew, Inglaterra, e cujo desdobramento seria a consequente perda do monopólio brasileiro.

O alerta dos malefícios do extrativismo predatório do látex foi expresso no ofício sobre a viagem ao rio Purus, onde alegava que a extração dava retorno financeiro menor que o cultivo. O trabalho irregular era propício aos maus costumes e provocava a carestia de alimentos na região (Silva Coutinho, 1865a). O historiador José Augusto Pádua (2004), referência na história ambiental brasileira, em sua obra Um sopro de destruição, ressaltou que 15 anos passados desde o primeiro trabalho de Silva Coutinho, Pimenta Bueno lamentava que o cultivo ainda não fosse prática no Brasil. Silva Coutinho temia a extinção de outras espécies, defendendo a imposição de regras também na extração de salsa, estopa e copaíba, e se posicionou contra o massacre de tartarugas.

Um dos principais projetos em que esteve envolvido foi a Expedição Thayer (1865-1866), assim denominada por ter sido financiada pelo milionário norte-americano Nathaniel Thayer Jr. (1808-1883), dirigida pelo naturalista e zoólogo Jean Louis Rodolphe Agassiz (1807-1873). Silva Coutinho acompanhou a equipe de Agassiz que procurava no Brasil evidências glaciais que comprovassem sua teoria antidarwinista, em caloroso debate na época (Brice, Figueirôa, 2001; Freitas, 2001). A hipótese defendida por Agassiz era a existência de um período glacial na América do Sul. Pelo que relatou o chefe da comissão no diário de viagem escrito em conjunto com sua esposa, Elizabeth Cary Agassiz (1822-1907), Silva Coutinho atuou no planejamento e na execução dos trabalhos da expedição, que incluiu facilitar os contatos sociais e também a realização de anotações geológicas e meteorológicas. Em algumas passagens, Agassiz faz comentários elogiosos a respeito do trabalho do engenheiro e dos conhecimentos que compartilhou, que contribuíram para o andamento da expedição: "Durante onze meses de intenso convívio, cada dia mais me louvei da feliz oportunidade que fez com que nos encontrássemos. Tive no major Coutinho um colaborador dos mais preciosos, de atividade e devotamento à ciência infatigáveis, um guia sem igual e um amigo cuja afeição espero conservar para sempre" (Agassiz, Agassiz, 1975, p.91, nota 14).

O diário ressalta a familiaridade de Silva Coutinho com a região amazônica resultante de viagens anteriores. Quando participou da Expedição Thayer, Silva Coutinho já havia explorado a geografia da região, estudado a natureza e aprendido a 'língua geral' e os costumes dos índios. Possuía rede de contatos formada por pessoas influentes e moradores brancos e indígenas, o que facilitava o trânsito e o trabalho, e oferecia conforto nos momentos de repouso. Ao discorrer sobre os Munduruku, cujos hábitos e costumes Silva Coutinho já havia estudado, Agassiz observa: "É de esperar que o major Coutinho, que na qualidade de engenheiro explorou os afluentes amazônicos e ao mesmo tempo estudou muito atentamente as tribos ribeirinhas, publique um dia os resultados de suas observações. A ele é que devemos a maior parte das informações que colhemos sobre o assunto" (Agassiz, Agassiz, 1975, p.197). 
Interesse expresso pela expedição e boa vontade oficial transparecem no relatório do Ministério da Agricultura, Comércio e Obras Públicas apresentado à Assembleia Legislativa e publicado no Suplemento do Almanaque Laemmert de 1867 (Almanak..., 1867). Sob o título "Comissão Agassiz", declarou ser de verdadeiro interesse do Império conhecer e explorar as tantas riquezas brasileiras, mas lamentou que isso não pudesse ser feito pelos próprios naturalistas brasileiros. Havia o desejo de criar uma comissão interna que acompanhasse o grupo de Agassiz; no entanto, por falta de verbas, o governo limitou-se a oferecer condições para a comissão norte-americana mediante a companhia de Silva Coutinho e do preparador Bomget, a oferta de transporte marítimo e a atenção dos presidentes de província que estariam à disposição:

Infelizmente as circunstâncias financeiras do país, não comportando despesas que, conquanto produtivas, podem ser adiadas; limitei-me a fazer acompanhar o ilustre professor pelo major de engenheiros Dr. João Martins da Silva Coutinho, o qual, além de ter provado, por mais de uma vez, suas habilitações científicas em comissões semelhantes, seu amor ao estudo, e ardor no trabalho, pelo conhecimento das localidades que tinham de ser visitadas, e da navegação dos rios, que deviam ser percorridos, e dos hábitos e costumes das tribos indígenas que demoram nas respectivas margens, devia ser de grande auxilio ao professor Agassiz para o cumprimento de sua missão. Tenho grande prazer em declarar, que o Sr. Agassiz publicamente reconheceu e agradeceu esse auxílio. Com este engenheiro foi também o preparador Bomget. Nos ofícios que o major Coutinho me dirigiu acerca de sua viagem, suscita diversas questões de grande interesse para o país, e ministra esclarecimentos preciosos, que podem ser aproveitados desde já. Esta comissão tem de exercer singular influência em quase todos os ramos dos conhecimentos humanos; profunda revolução, porém, deve de fazer na ciência ictiológica (Almanak..., 1867, supl., p.99).

A comissão de Agassiz tinha seus próprios objetivos, mas os interesses brasileiros eram contemplados com o levantamento das regiões e de seus aspectos naturais. Posteriormente, por iniciativa de Charles Frederick Hartt (1840-1878) - geólogo canadense e professor de Geologia na Universidade de Cornell (Ithaca, NY), que como aluno acompanhou Agassiz em sua viagem ao Brasil -, foi criada a Comissão Geológica do Império que, chefiada por ele, enviou expedições a diversas províncias do país e coletou farto material geológico e paleontológico (Figueirôa, 1997).

A consolidação profissional de Silva Coutinho, iniciada com sua formação na Escola Militar, deu-se através da participação em comissões fundamentais para o país, nas quais engenheiros militares atuavam nas delicadas questões de estabelecimento de fronteiras e manutenção da unidade territorial.

\section{O engenheiro civil}

Silva Coutinho também esteve envolvido na Exposição Universal de Paris de 1867, a quarta com participação brasileira. Esses eventos eram valorizados por significar para o país oportunidade de fazer propaganda da civilidade e dos atrativos da monarquia dos trópicos. Sendo assim, o imperador envolvia-se pessoalmente na preparação e realização do estande e comparecia nos dias de exposição. Em 1851, ocorreu a primeira exibição internacional desse 
tipo, e só 11 anos depois o Brasil fez sua estreia entre os expositores, buscando estar presente a partir de então. A exposição de 1867 ocorreu em meio à Guerra do Paraguai (1864-1870) e, apesar dos poucos recursos financeiros disponíveis, o país não deixou de marcar presença na cidade francesa, já que "perder uma feira era demonstrar fraqueza" diante do mundo moderno que queria impressionar (Schwarcz, 2006, p.396). Silva Coutinho compôs o júri (Villeneuve, 1868) e, em reconhecimento a sua atuação, recebeu cinco medalhas e foi agraciado por Napoleão III, que lhe concedeu o grau de cavaleiro da Legião de Honra.

Por ocasião da Exposição Universal de Viena, em 1873, Silva Coutinho, convidado a participar, declinou do convite, preferindo permanecer no Brasil, mas tornou a integrar o grupo brasileiro na exposição de 1876, na Filadélfia, inicialmente como secretário. A comissão enviada era composta ainda por Nicolau Joaquim Moreira, José Saldanha da Gama, Pedro Dias Gordilho Paes Leme e Hermenegildo Rodrigues de Alvarenga, tendo como presidente e vice-presidente os conselheiros Antonio Pedro de Carvalho Borges, barão de Carvalho Borges (1824-1888) e Felipe Lopes Netto (1814-1895), respectivamente. Todavia, próximo ao fechamento da exposição, Lopes Netto precisou deixar seu cargo, motivado por seu frágil estado de saúde, sendo substituído por Silva Coutinho, de acordo com indicação do conselheiro Carvalho Borges (Almeida, 1877, p.45). Dom Pedro II, por sua vez, não só foi verificar as exposições, mas também estava ao lado do presidente norte-americano Ulysses S. Grant (1822-1885) na cerimônia de abertura e no início dos trabalhos do Machinery Hall, uma das principais seções.

A exposição universal de 1876 realizou-se no ano de comemoração do centenário da independência dos EUA e, por isso, foi envolvida com retórica patriótica e valorização dos símbolos e personagens históricos do país (Gross, Snyder, 2005). Não por coincidência, a escolha da Filadélfia como sede da exposição decorreu de seu reconhecimento como berço do movimento de independência norte-americano. Nos seis meses de evento (de 10 de maio a 10 de novembro), os brasileiros buscaram atrair atenções e divulgar seu país através de distribuição de mapas e livros do Império aos visitantes ${ }^{4}$, à imprensa e aos diversos estados americanos, e da oferta - no espaço montado por um certo capitão Resende com auxílio do governo imperial - de café, mate e outros produtos servidos gratuitamente aos comissários dos países presentes e a preço popular ao público visitante. Silva Coutinho, em tom otimista, declarou que a comissão fora muito bem recebida por americanos e estrangeiros, e teve repercussão positiva nos jornais estrangeiros, mas alertou: "Não nos iludamos: o que mereceu aplausos na exposição foi quase tudo obra da natureza; o trabalho do homem entrou aí com pequena parcela, mas felizmente tanto quanto bastou para demonstrar que não somos indignos das riquezas que possuímos" (Silva Coutinho, 1878, p.30). De fato, entre os produtos exibidos, as invenções chamavam menos atenção do que os produtos naturais.

A opinião de Silva Coutinho sobre o país anfitrião, que consta do relatório oficial, era de admiração à sociedade religiosa, ordeira, dedicada ao trabalho e respeitosa da liberdade e dignidade humana. O Brasil, por sua vez, parecia-lhe ter como problema a tímida industrialização. A falsa ideia de que o homem branco não aguentaria o trabalho na agricultura fazia-o fugir, restando como mão de obra o escravo negro. O trabalho era feito de maneira primitiva e sob clima quente; no entanto, nem o clima e nem o solo impediam de avançar a produção; no uso de máquinas e no sistema de aperfeiçoamento da lavoura e do transporte, 
porém, havia diferença para o aumento da produção. Depois disso, previu ser necessário diversificar os produtos agrícolas e desenvolver a indústria fabril para aproveitar as matériasprimas, pois o sucesso no comércio do café não deveria ser considerado permanente e seguro. Quanto à 'recompensa', o júri premiou 436 dos 1.052 expositores brasileiros, seguindo a trajetória ascendente de premiações totais (em Londres foram 84; em Paris, 105; em Viena, 192), e o café levou 66 dos prêmios, superando o produzido em outros países. Ainda nos Estados Unidos Silva Coutinho examinou as estradas de ferro do norte e oeste do país com Bueno Filho, enquanto Hermenegildo Alvarenga examinou as ferrovias do sul.

De retorno ao Brasil, os membros da comissão trouxeram diversos estudos que fizeram ao longo de sua estada e também objetos obtidos mediante troca com outras comissões, como, por exemplo, a coleção mineralógica que o comissário de Michigan ofereceu ao Museu Nacional e amostras de minerais doadas pelo professor W.H.B. Thomaz. Além desse informe sobre a doação de exemplares de minerais para o Museu Nacional, também existem informações sobre os prejuízos ocorridos com a perda de "muitos minerais das coleções expostas pelo Museu do Rio de Janeiro" na exposição da Filadélfia (Lacerda, 1905, p.55). Em sua obra Fastos do Museu Nacional do Rio de Janeiro, João Baptista de Lacerda não fez referência às citadas doações, mas apontou outras perdas que o museu teve com empréstimos para as exposições internacionais, como os exemplares danificados na exposição de Chicago em 1893, que quando "restituídos ao Museu não puderam ser mais reparados" (p.55). Sobre esses e outros desastres recomendou que as remessas para as exposições só fossem efetuadas através das legações brasileiras, que poderiam utilizar todos os meios legais para a preservação do patrimônio do Museu Nacional.

Voltando na cronologia, no início da década de 1870, Silva Coutinho partiu em comissão, desta vez para São Paulo, percorrendo extensa região e fazendo o reconhecimento da estrada de ferro Sorocaba. Seus apontamentos e conclusões foram sistematizados e publicados em 1872 .

Em 1870 e 1871, ocorreram as chamadas Expedições Morgan ${ }^{5}$ que trouxeram Charles Frederick Hartt - que conhecia Silva Coutinho desde a Expedição Thayer - de volta ao Brasil. Nesses dois anos foram realizadas duas viagens, tendo Hartt vindo na primeira com uma comitiva de ajudantes e na segunda acompanhado apenas de Orville Adelbert Derby (18511915), seu discípulo e aluno na Universidade de Cornell, em Ithaca, onde Hartt lecionava geologia e geografia física. Em 1870, os trabalhos com coleta de fósseis foram realizados na região Nordeste, chegando aos baixos rios Tocantins, Tapajós e Xingu e ainda nos terrenos devonianos de Ererê e Monte Alegre. A escolha da serra do Ererê foi influenciada pela Expedição Thayer e a hipótese geológica de Louis Agassiz, pois o naturalista estivera nesse local acompanhado de Silva Coutinho na década anterior (Freitas, 2001; Figueirôa, 1997; Tosatto, 2001; Brice, Figueirôa, 2001). Em 1871 Hartt e Derby direcionaram seus esforços para o vale do Amazonas e o baixo Tapajós, onde conseguiram "montar uma coleção de fósseis carboníferos no calcário de Itaituba" (Tosatto, 2001, p.8). ${ }^{6}$

O governo brasileiro disponibilizou apoio técnico aos trabalhos das expedições de Hartt, como fazia com empreendimentos semelhantes. E, a exemplo do que aconteceu com Louis Agassiz, Hartt obteve com Silva Coutinho indicações e informações fundamentais. Com os resultados dessas expedições, Hartt elaborou argumentos próprios que refutaram a teoria dos depósitos de origem glacial defendida pelo chefe da Expedição Thayer, bem como escreveu sobre culturas indígenas. 
Charles Hartt voltou aos Estados Unidos ao final das expedições, mas não permaneceu muito tempo longe do Brasil e, em fins de 1874, retornou ao país. Graças a seus esforços, deu início e dirigiu a Comissão Geológica do Império do Brasil, entre 1875 e 1877. Segundo observação de Figueirôa (1997) corroborada por Freitas (2001), a Comissão aconteceu por conta da insistência e persuasão de Hartt junto ao imperador com relação à necessidade de produzir um mapa geológico do território brasileiro. Além do necessário e sistemático estudo geológico do Brasil, Hartt argumentou que a coordenaria com os olhos voltados para a preparação da Exposição Universal da Filadélfia. Depois de dois anos de atividades, o governo determinou a suspensão temporária da Comissão em 1ํo de julho de 1877; Hartt conseguiu prorrogá-la por mais seis meses, fazendo-a sobreviver até a mudança da conformação política para o gabinete liberal, em 1878. E tomou para si a tarefa de dar continuidade à extinta comissão, o que fez através da direção da Seção de Geologia, Mineralogia e Ciências Físicas do Museu Nacional; faleceu, entretanto, pouco tempo depois (em 18 de março do mesmo ano). Seu discípulo e amigo Orville Derby assumiu a função sem remuneração, só sendo contratado em 1879 e permanecendo no cargo até 1890.

A justificativa para o fim da expedição era de ordem econômica, embora tenha pesado a falta de resultados imediatos (Figueirôa, 1997). Se por um lado o imperador se empenhava em se colocar como grande incentivador e financiador da cultura e da ciência, bem como em levar adiante seu projeto de nação e construção da identidade brasileira, por outro faltou-lhe o apoio político nesse caso. Silvia Figueirôa (1997, p.150) destacou a importância da Comissão Geológica do Império por ser a "primeira iniciativa institucional, de abrangência nacional, no âmbito específico das ciências geológicas no Brasil".

Silva Coutinho não participou da Comissão Geológica do Império, embora certamente deva ter contribuído para suas atividades na indicação geológica e geográfica das localidades visitadas, a exemplo do ocorrido com as expedições anteriores. Uma das razões de sua não participação foi estar no cargo de diretor da Terceira Seção (Geologia, Mineralogia e Ciências Físicas) do Museu Nacional durante os trabalhos da Comissão, de fevereiro de 1875 a 1876.

Na década de 1880, Silva Coutinho participou da Exposição Antropológica Brasileira em 1881 e, em 1886, em viagem ao Rio Grande do Norte, descobriu rochas fossilíferas do Cretáceo. Esta última informação é baseada, de acordo com Vingt-Un Rosado (1998), em anotação feita por Orville Derby na monografia de Charles Abiathar White (1887) intitulada "Contribuições à Paleontologia do Brasil", fonte de todas as referências de autores posteriores. Vingt-Un Rosado comentou que Derby não indicou nenhuma fonte escrita em que Silva Coutinho tenha comunicado suas descobertas dos fósseis de Mossoró. Acrescenta, entretanto, que Silva Coutinho só esteve no Rio Grande do Norte uma vez, exatamente em 1886, devendo ter chegado por terra, provavelmente a cavalo, pois não existe registro de seu nome na lista de passageiros dos vapores da Companhia Pernambucana.

\section{Silva Coutinho e o sistema ferroviário brasileiro}

Na trajetória profissional de Silva Coutinho existem alguns aspectos que são mais evidentes, como seu interesse pelos temas amazônicos. São identificáveis diversos momentos em que ele esteve na região, pelo menos, desde a expedição pelos rios Purus e Madeira em 1861, e os 
documentos mostram que seus contemporâneos o identificavam como grande conhecedor daquela área, o que tem endosso nas suas publicações posteriores. Louis Agassiz chegou a afirmar que o engenheiro detinha conhecimentos enciclopédicos (Vultos..., 1942; Rosado, 1991). Ao lado desse tema, sobre o qual publicou vários trabalhos, podemos destacar seu papel como engenheiro responsável por grandes extensões das estradas de ferro imperiais. Cuidou da instalação e do prolongamento de alguns trechos, foi diretor das companhias de estradas de ferro Leopoldina, São Paulo do Muriaé e Grão-Pará, integrou comissões de reforma de tarifas ferroviárias (Jornal..., 12 out. 1889) e ainda foi membro vogal da comissão executiva brasileira na Exposição Internacional dos Caminhos de Ferro realizada em Paris em 1886.

Vale ressaltar que Silva Coutinho teve a ideia de construir uma estrada de ferro que substituísse a navegação do rio Madeira. Em 1861, o presidente da província do Amazonas, Manuel Clementino Carneiro da Cunha (1825-1890), contratou o engenheiro (ainda militar) para estudar o referido rio e planejar a sua navegação e colonização. Ao fim da viagem, Silva Coutinho redigiu um relatório ao presidente e apresentou a ideia de construir uma ferrovia que cobrisse o trecho das cachoeiras do rio Madeira e o ligasse ao rio Mamoré: "Da primeira à última cachoeira há 70 léguas, segundo o major Serra. O melhor meio de transpor este obstáculo é abrir uma estrada que ligue os dois pontos extremos, pela margem direita. A estrada pode vir a ter 50 léguas, em consequência da grande curva que descreve o rio ao poente" (Silva Coutinho, 1861, p.28).

O professor e escritor Francisco Foot Hardman (1988) e o engenheiro e jornalista Manuel Rodrigues Ferreira (2005) publicaram livros em que trataram da implantação do trecho Madeira-Mamoré e afirmam que o general boliviano Quentin Quevedo lançou essa ideia simultaneamente. Sem importar quem foi o primeiro a expor a proposta, os argumentos utilizados pelo brasileiro foram políticos, econômicos e geográficos, sobretudo com relação à comunicação com o Mato Grosso que era feita pelo rio Paraguai: “O Madeira é o caminho natural da província do Mato Grosso, e devia ser preferido ao Paraguai, pela razão altamente política de pertencer-nos exclusivamente" (Silva Coutinho, 1861, p.27). O transporte ferroviário era alternativa segura diante do difícil caminho do rio.

O que se seguiu à ideia de meados do século XIX não foi uma história feliz. O início da implantação ocorreu com o Tratado de Petrópolis entre Brasil e Bolívia em 1903. Dos trabalhadores importados de diversos países, muitos foram vítimas de doenças tropicais e por isso os nomes sugestivos que servem de título para os livros e para nomenclatura popular da ferrovia - Trem-fantasma, de Francisco Hardman (1988), e A ferrovia do diabo, de Manuel Ferreira (2005). Mal aproveitada, a estrada de ferro Madeira-Mamoré foi desativada na década de 1970 e sofreu degradação do tempo e roubos sistemáticos. Hoje, pairam sobre ela promessas de que volte a funcionar.

Ainda no tema das ferrovias, em 1886 Silva Coutinho apresentou ao conselheiro e ministro da Agricultura Antonio da Silva Prado (1840-1929) um minucioso estudo sobre as estradas de ferro do norte do Império, que culminou no Relatório apresentado ao conselheiro Antonio da Silva Prado, publicado inicialmente em 1888 (Silva Coutinho, 1998). O engenheiro oferecera seus serviços ao conselheiro imperial, que o aceitou prontamente e o encarregou de:

estudar e informar o estado da viação férrea da região que ele ia percorrer, em províncias do Norte, e indicar as medidas mais urgentes para melhorar a existência das populações 
e aliviar os ônus do Estado e ao mesmo tempo apresentar o seu parecer técnico sobre os prolongamentos das estradas de ferro de Bahia e Pernambuco, prosseguindo da Estrada de Ferro Conde d'Eu até Cabedello, e a ramificação da Estrada de Ferro de Natal a Nova Cruz, pelo vale da Ceará-Mirim (Doutor João..., 1906, p.X).

Silva Coutinho percorreu trechos de ferrovias que passavam pelo Ceará, Rio Grande do Norte, Paraíba, Pernambuco, Alagoas e Bahia e, mais tarde, escreveu seus apontamentos e conclusões do que seria um diagnóstico da situação encontrada. De maneira geral, o relatório fornece informações geográficas e sobre os produtos locais, atesta o estado de conservação/ deterioração, o uso e o lucro das estradas de ferro e, como engenheiro, não deixa de aconselhar o governo sobre futuras medidas que poderiam gerar melhor proveito ou de indicar o que para ele corresponderia a um gasto inútil de dinheiro. Seus apontamentos tendem a defender a manutenção das ferrovias já existentes utilizando como justificativa questões da época referentes à integração e comunicação com locais mais afastados, e o progresso da civilização. Foi desse trabalho que resultou boa parte das amostras petrográficas por ele coletadas no Nordeste e que se encontram no atual acervo do Museu Nacional.

\section{0 reconhecimento}

No dia 12 de outubro de 1889, os leitores do Jornal do Comércio foram informados na primeira página do falecimento de Silva Coutinho, ocorrido na véspera. Ele, que exercia então a função de consultor técnico no Ministério da Agricultura, estava em Paris, e os médicos atribuíram sua morte a uma 'febre perniciosa'. Junto da notícia, o jornal incluía breve biografia daquele que considerava "um dos mais antigos e considerados engenheiros brasileiros". Silva Coutinho fora a Paris para participar de mais uma exposição universal e aproveitou para comparecer ao congresso presidido pelo engenheiro Alexandre Gustave Eiffel (1832-1893), responsável pela construção da torre que leva seu nome, que tinha como tema os processos de construção. Longe de seu país e após sucessivos dias de baixa temperatura, adoeceu quando acompanhava a utilização do material que serviria para as obras de abastecimento de água da cidade de Niterói (Doutor João..., 1906, p.XII).

As manifestações de homenagem ao engenheiro aparecem nas edições seguintes do jornal. Como Silva Coutinho fora professor da Escola Central, foi lembrado em pronunciamento feito pelo engenheiro e professor Antônio de Paula Freitas (1843-1906) antes de sua aula aos estudantes da cadeira de estradas da Escola Politécnica. Paula Freitas manifestou ter pelo engenheiro respeito e saudades, "além de ser um engenheiro conceituado, e de ter a vantagem de conhecer o Brasil de norte a sul, e de leste a oeste, em tudo quanto respeita a sua geologia, fauna e flora, e aos melhoramentos materiais que possui, e de que ainda carece" (Jornal..., 13 out. 1889). Quatro anúncios no Jornal do Comércio do dia 16 convidavam para a missa a ser realizada na Igreja de São Francisco de Paula, no Centro da cidade.

Silva Coutinho era membro de sociedades científicas brasileiras e internacionais e, entre elas, foi o primeiro presidente e membro do conselho diretor do Clube de Engenharia, bem como sócio remido da Associação Promotora de Instrução. Foi agraciado por Isabel II da Espanha, a Católica, como cavalheiro real da Ordem de Isabel; com a Ordem de Cristo de 
Portugal; como oficial da Legião de Honra da França; e, no Brasil, seguidamente com a Ordem da Rosa até sua elevação a grão-dignitário (Jornal..., 12 out. 1889).

Além dos serviços, outra parte do legado de Silva Coutinho é constituída por seus escritos que versam sobre rios, cacau, guaraná, seringueiras, gomas e resinas, palmeira piaçava, mandacarus, coqueiro da Bahia, floresta da Tijuca, indústria da seda, aclimatação da maniçoba e carnaubeira, geologia, Exposição Universal da Filadélfia, estradas de ferro, comércio, importação e exportação, e, de maneira geral, trazem um pouco de suas concepções sobre seu tempo, o que transcende os temas centrais e representa sua contribuição intelectual.

Para quem hoje visita a sede do Clube de Engenharia, no Rio de Janeiro, o nome de seu primeiro presidente não parece fazer parte da construção da memória da instituição Seu nome consta entre os fundadores e, depois de sua presidência, que durou de 24 de dezembro de 1880 a 3 de novembro de 1881, figurou entre os membros do Conselho Diretor. Silva Coutinho foi lembrado em três números da revista impressa pela instituição no período republicano: 1906, 1922 (edição comemorativa do Centenário da Independência) e 1956. Elogio histórico relembra sua trajetória "cheia de serviços valiosíssimos à sua pátria, nas árduas e importantes comissões que lhe foram confiadas, as quais ele soube sempre desempenhar com muito critério, tino superior e rara inteligência" (Doutor João..., 1906, p.VII). No último parágrafo da homenagem, considera-se que sua ausência representava enorme vazio tanto para a engenharia quanto para o país ao qual ele sempre serviu com afinco (Doutor João..., 1906, p.XII).

A trajetória do engenheiro João Martins da Silva Coutinho foi marcada pelo exercício científico sob promoção do governo imperial, possibilitando que atuasse profissionalmente em diversas províncias brasileiras, bem como em outros países, representando o Brasil, como por ocasião das exposições universais. Ao que parece, transitava de maneira confortável entre políticos e entre outros naturalistas da época. Recebeu convites dos primeiros para o cargo de ministro e mesmo de presidente da província do Amazonas. Como engenheiro, era um dos profissionais mais importantes no caminho da modernização e teve reconhecimento social, como pôde até aqui ser verificado. Sua vida terminou no mesmo ano da derrocada do regime liderado por dom Pedro II e marcado pela proclamação da República. Em sua trajetória profissional, manteve sempre ligação com o Museu Nacional, instituição em que ocupou cargos administrativos e para a qual contribuiu como cientista e colaborador para a formação de suas coleções geológicas.

\section{A atuação no Museu Nacional}

O vínculo estabelecido entre Silva Coutinho e o Museu Nacional remete, ao menos indiretamente, a seus tempos de estudo na Escola Militar, onde assistiu a aulas ministradas por distintos intelectuais da época, muitos dos quais se reuniam no Museu ocupando cargos e participando de discussões. Já no período de formação esteve em contato com homens que seriam mais tarde seus companheiros em espaços de sociabilidade no Rio de Janeiro, como as sociedades científicas e o Museu. Foram seus professores, por exemplo, os engenheiros Frederico Leopoldo Cesar Burlamaque (1803-1866), diretor do museu e da Terceira Seção, e Guilherme de Capanema. 
Silva Coutinho fez parte do quadro administrativo do Museu Nacional por breve período. Em 11 de novembro de 1874, Freire Allemão faleceu deixando em aberto os cargos que acumulava, de diretor da instituição e da Terceira Seção, de Mineralogia, Geologia e Ciências Físicas. Silva Coutinho foi designado para ocupá-la, por decreto de 26 de fevereiro de 1875. No mesmo mês, no dia 13, houve a nomeação do engenheiro Antonio José Ribeiro da Cruz Rangel como supranumerário da Terceira Seção e, em 29 de maio, tornou-se adjunto (Livro..., 29 maio 1875), cargo ocupado por Guilherme de Capanema desde 1849. Nessa reorganização dos funcionários, a diretoria-geral ficou sob responsabilidade de Ladislau de Souza Mello e Netto (1838-1894), que já a exercia como interino há dois anos em decorrência do necessário afastamento de Freire Allemão, bem como a direção da Seção de Botânica, Agricultura e Artes Mecânicas. A Primeira Seção, de Zoologia, Fisiologia e Anatomia Comparada, permaneceu com João Joaquim Pizarro (1842-1906) até 1883, e Manuel de Araújo Porto-Alegre, barão de Santo Ângelo (1806-1879) ocupava a Quarta Seção, de Numismática, Arqueologia, Usos e Costumes das Nações Modernas.

Não foram encontrados registros que permitissem conhecer a data exata em que Silva Coutinho deixou a função. Sabe-se que em meio à reformulação de 1876 e em decreto de 9 de fevereiro, continuava no cargo; no entanto, logo a direção passou a ser ocupada por Charles Hartt, que em março organizava uma coleção de minerais no museu (Livro..., 21 mar. 1876). Hartt ocupava simultaneamente a direção da Comissão Geológica do Império e, assim, quem de fato cuidava dos assuntos da Terceira Seção era o então subdiretor Carlos Luiz de Saules Junior (?-1878). Isso fica evidente quando, em 18 de abril de 1876, foi pedida para ele gratificação equivalente à de diretor de seção por conta da ausência do diretor efetivo (Livro..., 18 abr. 1876). Hartt permaneceu como diretor formal até o final de dezembro de 1876, quando passou a se dedicar integralmente à comissão geológica, e Saules Junior tornou-se interino.

No intervalo que Silva Coutinho dirigiu a Terceira Seção finalizou-se o processo de aquisição e incorporação ao acervo do Museu Nacional de minerais pertencentes a frei Custódio Alves Serrão (1799-1873). A negociação envolvendo sua coleção particular, que vinha sendo desenvolvida com os herdeiros do falecido diretor, culminou com sua compra. A seção também ganhou um conjunto de conchas fósseis oferecidas por Charles Hartt (Livro..., 29 maio 1875; Avisos..., 29 maio 1875), bem como recebeu, através do consulado da Alemanha, do diretor do Museu Mineralógico da Universidade de Göttingen, requisição de material de mineralogia (Avisos..., 5 out. 1875; Livro..., 15 out. 1875). Prática recorrente, o museu alemão propunha permuta e compra de material de Minas Gerais.

Apesar da curta estada, suas contribuições ao museu foram reconhecidas por seus contemporâneos, sendo-lhe, aliás, ofertado pelo diretor Ladislau Netto o cartão de entrada franca, em 1878:

Havendo em alto apreço e em grande utilidade para o engrandecimento do Museu Nacional os serviços por V. Sa . [João Martins da Silva Coutinho] tantas vezes e de modo tão conspícuo a ele prestados, como dedicado que é às Ciências Naturais em geral, tenho a honra de oferecer a V. S ${ }^{a}$. um cartão de franco ingresso nos salões e laboratórios deste Museu, durante as horas do nosso serviço diário, rogando-lhe se digne de aceitá-lo como pequena prova de súbita distinção, que a V. S ${ }^{\text {a }}$. tributa a Diretoria deste Museu (Livro..., 6 set. 1878). 
O museu era aberto ao público apenas aos domingos, e o cartão dava direito à entrada nas instalações, durante o tempo de expediente, sem restrição de hora ou data (Almanak..., 1876); logo, o recebimento por Silva Coutinho ratificou sua ligação com o Museu Nacional e seus membros, e, de certa forma, deu-lhe liberdade de circulação equivalente à de um funcionário formal.

A permanência de Silva Coutinho no comando da Terceira Seção coincide com o período profícuo pelo qual passou o Museu Nacional sob direção de Ladislau Netto, que o contemporâneo João Baptista Lacerda (1905) classificou como a "idade do ouro" do museu, na qual se insere a reforma de 1876, que colaborou para a afirmação e o prestígio da instituição científica no país e internacionalmente. Segundo a historiadora Maria Margaret Lopes (1997, p.149), nesses anos iniciais da direção de Ladislau Netto foi inaugurado um "novo ideal de funcionamento" dedicado a aumentar e organizar as coleções de acordo com os resultados de minuciosas análises e acompanhar as rápidas modificações científicas que ocorriam em termos de classificação de material.

\section{O envio de amostras para o Museu Nacional}

Quanto aos serviços prestados pelo engenheiro ao Museu Nacional, a principal contribuição foi o fornecimento de material incorporado às coleções, que superou sua atuação no cargo maior da Terceira Seção. Suas atividades em comissões estavam em grande medida ligadas direta ou indiretamente ao Museu e não só contribuíam para o conhecimento científico desenvolvido no Brasil, como para o crescimento da instituição. Pode-se dizer que em seus trabalhos de campo, mesmo durante aqueles estudos de caráter mais técnico, teve sempre a preocupação de fazer apontamentos geológicos e coletar amostras, principalmente rochas, como verificamos em suas remessas.

Destaca-se a Comissão Científica do Império que explorou as províncias do Norte e Nordeste de 1859 a 1861, da qual Silva Coutinho foi um dos participantes, junto com o barão de Capanema e o conselheiro Freire Allemão, ambos do Museu. O esforço dos membros da comissão foi responsável pelo envio de importante material coletado para análise e composição de acervo, mas também de livros e instrumentos. Da mesma forma, as comissões de exposições universais fizeram consistentes doações.

Como espaço científico o Museu Nacional, por intermédio de seus diretores e do governo imperial, mobilizava-se em prol da complementação de seu acervo. Desde as primeiras gestões foram formuladas solicitações de envio de material a naturalistas viajantes, instituições e províncias. Assim, foi esse também o destino de parte do material coletado em campo por Silva Coutinho.

Nos livros de registro de avisos e ofícios encontram-se as mais detalhadas referências de material enviado por iniciativa de Silva Coutinho, então diretor das Obras Públicas da província do Amazonas. Em 1864, foi confirmado pelo então diretor o recebimento de uma grande remessa: 28 amostras de argila de diferentes cores; sete rochas calcárias, carbonatos e sulfatos; 19 rochas quartzosas e feldspáticas; 34 rochas de concreção e minério de ferro em decomposição; quatro rochas concrecionadas com presença de óxido de manganês; mais quatro amostras de madeira fóssil, de dois tipos, passando ao linhito. A maioria foi obtida em 
rios (Avisos..., 24 nov. 1864), o que certamente ocorreu enquanto Silva Coutinho explorava o rio Purus e o rio Madeira e seus afluentes a pedido do presidente da província.

Outra remessa, com trinta volumes de amostras geológicas e botânicas da mesma procedência, chegou em 1866 (Livro..., 27 abr. 1866). Meses depois, o governo imperial designou Silva Coutinho para organizar a coleção mineralógica do Museu Nacional, tendo em vista os trabalhos da Comissão Diretora da Exposição Nacional (Livro..., 29 ago. 1866).

Já em 1867, Silva Coutinho enviou um ovo (sem indicação de procedência) e, dois anos depois, 21 caixotes e "outros objetos" vindos especificamente do vale do rio Branco, também no Amazonas, destinados a análise e alocação (Livro..., 11 nov. 1869; Avisos..., 11 nov. 1869). No mesmo ano, o museu publicou em relatório o recebimento de "coleções mineralógicas e botânicas" também provindas daquele vale, que foram obtidas durante os trabalhos da comissão de que o engenheiro era membro (Albuquerque, 1870, p.89). Com o mesmo ano de chegada e local de origem, pode-se considerar tanto a possibilidade de se tratar da mesma remessa nos dois documentos, como a de que sejam remessas diferentes. Outra observação importante é que Silva Coutinho esteve em diferentes comissões na Amazônia nessa década, sendo difícil precisar em qual (ou quais) delas teria separado esse material.

Do Amazonas, ele trouxe óleo de copaibarana ou falsa copaíba. Sob os cuidados do Museu Nacional, despertou atenção de pessoas que, em nome da Faculdade de Medicina da Corte, pedem uma certa quantidade para realizar experiências (Livro..., 29 nov. 1869).

Em certa ocasião, chegou às mãos de Ladislau Netto o relatório da exploração geológica dos rios Tocantins e Tapajós escrito por Charles Hartt. Finda a leitura, Ladislau Netto comentou o trabalho e colocou-se firmemente contra a afirmação de que Hartt era descobridor do terreno carbonífero no Amazonas, o que, em sua opinião, não passava de um engano, fruto da ignorância de Hartt sobre a atuação dos brasileiros. Silva Coutinho estivera lá antes e era especialista na região. A favor dele havia a doação de exemplares: "Encontram-se nesse museu numerosos objetos colhidos por ele naquela região - objetos de entre os quais dou-me pressa de mencionar alguns braquiópodes fósseis dos gêneros Productus, Terebratula e creio que Spirifer tambur", que foram, aliás, apresentados na Exposição Nacional de 1867 junto com algumas rochas. Os exemplares serviriam de "distintivos do terreno carbonífero na Europa e Estados Unidos da América" (Livro..., 5 abr. 1871). Apesar de seu objetivo ser de outra natureza, o ofício de Ladislau Netto é ilustrativo quanto a doações de fósseis e rochas da Amazônia. De fato, as conchas fósseis do rio Branco chegam ao museu no mesmo ano do ofício, remetidas pela Secretaria da Agricultura, e, dos objetos adquiridos, constam Productus, Terebratula e Spirifer.

Além dessas amostras do Amazonas, Silva Coutinho encaminhou à Quarta Seção um artefato e um cachimbo de barro. O primeiro foi encontrado "a 12 palmos de profundidade em um Sambaqui, próximo da Ribeira, São Paulo, a 6 léguas da Costa" e o outro, a dez palmos (Livro..., 30 nov. 1872). Sem informações adicionais, mandou uma pequena coleção de amostras geológicas originárias de São Paulo (Livro..., 31 ago. 1868; Avisos..., 31 ago. 1868). A chegada de uma coleção de rochas com fósseis vindas das províncias do Norte é registrada no livro de entrada no dia 7 de maio de 1885 (Livro..., 7 maio 1885). A última doação feita por ele é uma amostra de borracha e dois vidros de azeite de 'piassaba', da ilha de Marajó, em 1889 (Tabela 1). 
Tabela 1: Material enviado por Silva Coutinho identificado em documentos do Setor de Memória e Arquivo do Museu Nacional*

\begin{tabular}{|c|c|c|c|}
\hline Amostra & Localização & Ano & Documento \\
\hline $\begin{array}{l}\text { Coleção mineral contendo } 28 \text { argilas de diferentes } \\
\text { cores, sete rochas calcárias, carbonatos e sulfatos, } \\
19 \text { rochas quartzosas e feldspáticas, } 34 \text { rochas de } \\
\text { concreção e minério de ferro em decomposição, } \\
\text { quatro rochas concrecionadas, contendo óxido de } \\
\text { manganês e quatro amostras de duas variedades } \\
\text { de madeira fóssil, passando ao linhito. }\end{array}$ & Amazonas & 1864 & Doc. MN, RA5/D5, p.87, 24/11/1864 \\
\hline Trinta volumes de amostras geológicas e botânicas & Amazonas & 1866 & Doc. MN, RA5/D5, p.119v, 27/04/1866 \\
\hline Um ovo de socó & & 1867 & Doc. MN, RA5/D5, p.164v, 07/01/1868 \\
\hline Pequena coleção geológica & São Paulo & 1868 & Doc. MN, RA5/D5, p. 179, 31/08/1868 \\
\hline Óleo de copaibarana ou falsa copaíba & Amazonas & 1869 & Doc. MN, RA6/D6, p.7-7v, 29/11/1869 \\
\hline 21 caixotes e objetos & $\begin{array}{l}\text { rio Branco, } \\
\text { Amazonas }\end{array}$ & 1869 & Doc. MN, RA6/D6, p. 6, 11/11/1869 \\
\hline Coleções mineralógicas e botânicas & $\begin{array}{l}\text { rio Branco, } \\
\text { Amazonas }\end{array}$ & 1869 & Relatório do Museu de 1869 (1870) \\
\hline $\begin{array}{l}\text { Conchas fósseis de braquiópodes: Productus, } \\
\text { Terebratula e (talvez) Spirifer tambur }\end{array}$ & $\begin{array}{l}\text { rio Branco, } \\
\text { Amazonas }\end{array}$ & 1871 & Doc. MN, RA6/D6, p.78, 30/03/1872 \\
\hline Um artefato de barro e um cachimbo de barro & São Paulo & 1872 & Doc. MN, RA6/D6, p.110, 30/11/1872 \\
\hline Coleção de rochas e fósseis & $\begin{array}{l}\text { Províncias } \\
\text { do Norte }\end{array}$ & 1885 & $\begin{array}{l}\text { Livro de Entrada do Museu Nacional, } \\
\text { D303, 1876-1892, p. } 225\end{array}$ \\
\hline $\begin{array}{l}\text { Amostra de borracha e dois vidrinhos de azeite de } \\
\text { 'piassaba' }\end{array}$ & Marajó & 1889 & $\begin{array}{l}\text { Livro de Entrada e Saída da Segunda } \\
\text { Seção, D305, 1885-1892 }\end{array}$ \\
\hline
\end{tabular}

*A identificação do ano refere-se a chegada ao Museu Nacional. As siglas referem-se a "Documento do Museu Nacional, Livro de Registro de Avisos e Ofícios", sendo os livros identificados pelo período abordado: RA5/D5 (1861-1869) e RA6/D6 (1869-1875)

Tendo as etiquetas de identificação das amostras encontradas na coleção de petrografia como fontes, são 36 as que apontam Silva Coutinho como coletor. Somam 14 as amostras de granito (sendo um granito pegmatítico) vindas de diferentes cortes da estrada de ferro de Baturité, no Ceará. Apenas sete, contudo, têm identificação da data e remetem a 1887. Do mesmo local, estão registradas ao menos quatro amostras de quartzito micáceo e quatro de gnaisse.

Outra amostra de granito foi coletada na estrada de ferro da Bahia (no quilômetro 292), bem como uma de quartzito verde, três de gnaisse, uma de micaxisto e uma de pegmatito. Da Bahia, aparecem ainda uma amostra de granito róseo obtida entre Vila Nova e Itiuba, além de amostra de xisto a uma légua de Vila Nova (Tabela 2).

Finalizando as indicações de amostras coletadas por ele apresentadas pelas etiquetas, temos gnaisse da Bahia central, gnaisse vindo de Paulo Afonso, rio São Francisco, em Alagoas e calcário cristalino obtido ao longo do rio Murié, em Campos dos Goytacazes, estado do Rio de Janeiro, sendo esta última datada de 1885 (Tabela 2). 
Tabela 2: Amostras de rochas enviadas por Silva Coutinho que se encontram na coleção de petrografia do Museu Nacional*

\begin{tabular}{|c|c|c|c|}
\hline Número & Amostra & Procedência & Ano \\
\hline \multicolumn{4}{|c|}{ Rochas ígneas } \\
\hline 1 & Granito & Estrada de Ferro de Baturité, corte 33, CE & 1887 \\
\hline 2 & Granito & Estrada de Ferro de Baturité, corte $41, \mathrm{CE}$ & $?$ \\
\hline 4 & Granito & Estrada de Ferro de Baturité, corte $27, \mathrm{CE}$ & $?$ \\
\hline 5 & Granito & Estrada de Ferro de Baturité, corte $49, \mathrm{CE}$ & $?$ \\
\hline 7 & Granito & Estrada de Ferro de Baturité, corte 34, CE & $?$ \\
\hline 8 & Granito & Estrada de Ferro de Baturité, corte $37, \mathrm{CE}$ & $?$ \\
\hline 10 & Granito & Estrada de Ferro de Baturité, corte $38, \mathrm{CE}$ & $?$ \\
\hline 24 & $\begin{array}{l}\text { Granito } \\
\text { pegmatítico }\end{array}$ & Estrada de Ferro de Baturité, corte $28, \mathrm{CE}$ & $?$ \\
\hline 246 & Granito & Estrada de Ferro de Baturité, corte $56, \mathrm{CE}$ & 1887 \\
\hline 247 & Granito & Estrada de Ferro de Baturité, corte $42, \mathrm{CE}$ & 1887 \\
\hline 248 & Granito & Estrada de Ferro de Baturité, corte $72, \mathrm{CE}$ & 1887 \\
\hline 250 & Granito & Estrada de Ferro de Baturité, corte $45, \mathrm{CE}$ & 1887 \\
\hline 253 & Granito & Estrada de Ferro de Baturité, corte $65, \mathrm{CE}$ & 1887 \\
\hline 473 & Granito & Estrada de Ferro de Baturité, corte $56, \mathrm{CE}$ & 1887 \\
\hline 477 & Granito & Estrada de Ferro da Bahia, km 292, BA & 1887 \\
\hline 481 & Granito róseo & Idem, entre Vila Nova e Itiuba, BA & 1887 \\
\hline 496 & Pegmatito & Estrada de Ferro da Bahia, km 298, BA & 1887 \\
\hline \multicolumn{4}{|c|}{ Rochas metamórficas } \\
\hline $11 / \mathrm{CE}$ & $\begin{array}{l}\text { Quartzito } \\
\text { micáceo }\end{array}$ & Estrada de Ferro de Baturité, corte 71, CE & $?$ \\
\hline $13 / \mathrm{CE}$ & $\begin{array}{l}\text { Quartzito } \\
\text { micáceo }\end{array}$ & Estrada de Ferro de Baturité, corte $73, \mathrm{CE}$ & $?$ \\
\hline 14 & $\begin{array}{l}\text { Quartzito } \\
\text { micáceo }\end{array}$ & Estrada de Ferro de Baturité, corte $67, \mathrm{CE}$ & $?$ \\
\hline 15 & $\begin{array}{l}\text { Quartzito } \\
\text { micáceo }\end{array}$ & Estrada de Ferro de Baturité, CE & $?$ \\
\hline 16 & $\begin{array}{l}\text { Quartzito } \\
\text { micáceo }\end{array}$ & Estrada de Ferro de Baturité, corte $74, \mathrm{CE}$ & $?$ \\
\hline 17 & Gnaisse & Estrada de Ferro de Baturité, corte $72, \mathrm{CE}$ & $?$ \\
\hline 18 & $\begin{array}{l}\text { Quartzito } \\
\text { micáceo }\end{array}$ & Estrada de Ferro de Baturité, corte $70, \mathrm{CE}$ & $?$ \\
\hline 194 & Gnaisse & Estrada de Ferro de Baturité, corte $59, \mathrm{CE}$ & $1887 ?$ \\
\hline 284 & Gnaisse & $\begin{array}{l}\text { Estrada de Ferro da Bahia, km 308, Oitava } \\
\text { Seção, BA }\end{array}$ & 1887 \\
\hline 292 & Gnaisse & Estrada de Ferro da Bahia, km 298, BA & 1887 \\
\hline 293 & Gnaisse & $\begin{array}{l}\text { Estrada de Ferro da Bahia, km 308, Oitava } \\
\text { Seção, BA }\end{array}$ & 1887 \\
\hline 386 & Gnaisse & km 1 a 6 da Cachoeira, BA & 1887 \\
\hline 400 & Gnaisse & Paulo Afonso, rio São Francisco, AL & $?$ \\
\hline 434 & Micaxisto & $\begin{array}{l}\text { Estrada de Ferro da Bahia, perto do km } 300 \\
\text { ou 305, BA }\end{array}$ & $?$ \\
\hline 684 & Xisto & Idem, 1 légua de Vila Nova, Missões, BA & $?$ \\
\hline 776 & Quartzito verde & Estrada de Ferro da Bahia, km 285, BA & 1887 \\
\hline 400 & Gnaisse & Paulo Afonso, rio São Francisco, AL & $?$ \\
\hline 524 & Calcário cristalino & Muriaé, Campos dos Goytacazes, RJ & 1885 \\
\hline 1934 & Gnaisse & Estrada de Ferro de Baturité, corte $64, \mathrm{CE}$ & $?$ \\
\hline 2004 & Gnaisse & Estrada de Ferro de Baturité, corte $64, \mathrm{CE}$ & 1887 \\
\hline
\end{tabular}

*As interrogações indicam a falta de datas nas etiquetas das amostras, provavelmente referentes ao ano de 1887 
A maior parte do material etiquetado (como indicam as referências de origem) e também as amostras de São Paulo sugerem relação com os trabalhos de Silva Coutinho nas estradas de ferro, quando percorreu aquelas regiões. Cabe destacar a existência de numerosos exemplares que coincidem em termos de classificação e localidade, mas, por não conter referências diretas ao engenheiro, não foram citados neste artigo.

Percebe-se que as remessas registradas nos livros do Museu Nacional fornecem informações pouco precisas e apresentam enorme ausência de detalhes, que seriam fundamentais para buscá-las nas coleções hoje pertencentes ao Departamento de Geologia e Paleontologia e que antigamente fizeram parte da Terceira Seção. Isso dificulta também afirmações vinculando as amostras com o que fazia Silva Coutinho na região em que as obteve, até porque os documentos não indicam a data da coleta. As etiquetas possuem características muito semelhantes, algo que pode ser explicado em parte por sua função - mera identificação objetiva do exemplar. Outro ponto a ser enfatizado diz respeito à natureza dos exemplares enviados, que indica seu interesse maior pela geologia e paleontologia, ainda que sem perder a oportunidade de coletar outros materiais que considerasse interessante encaminhar ao Museu Nacional, constando, como atestou Ladislau Netto (1870), da "Relação dos doadores do Museu Nacional".

\section{Considerações finais}

Ao longo de sua vida profissional Silva Coutinho contribuiu significativamente de diversas formas para o Museu Nacional. Legou informações importantes sobre as regiões amazônicas, fruto de sua intensa participação e diversificadas atividades nas comissões científicas; organizou coleções mineralógicas para a participação em grandes exposições e remeteu amostras de história natural para o crescimento do acervo científico da instituição. Amostras petrográficas presentes no acervo do Departamento de Geologia e Paleontologia atestam seu grande interesse pela instituição, constituindo-se hoje em acervo de significativo valor histórico e científico para o Museu Nacional.

\section{AGRADECIMENTOS}

À especialista em arquivos Silvia Ninita de Moura Estevão, à assistente administrativa Ana Maria de Pompéia Macedo e ao historiador Gustavo Alves Cardoso Moreira pelo auxílio e disponibilização dos documentos do Setor de Memória e Arquivo do Museu Nacional. À doutora Silvia Figueirôa, do Instituto de Geociências da Universidade Estadual de Campinas, pelas críticas e sugestões.

\section{NOTAS}

* Esta pesquisa recebeu auxílio financeiro do Conselho Nacional de Desenvolvimento Científico e Tecnológico (CNPq, processo 305078/2006-2 e 301328/2009-9 - Bolsa de Produtividade - e processo 401762/2010-6 Edital "Fortalecimento da Paleontologia Nacional"). Contou também com bolsa do Programa Institucional de Bolsas de Iniciação Científica da Universidade Federal do Rio de Janeiro.

${ }^{1}$ A reforma da Escola Militar de 1844 determinou que, findo o curso de sete anos, se recebesse o título de bacharel e, se aprovado plenamente em todos os anos, o título de doutor (Castro, 2004). De fato, Silva Coutinho tem seu nome precedido ora por um, ora por outro termo.

${ }^{2}$ O Jornal do Commercio de 12 de outubro de 1889 afirma que Silva Coutinho foi também astrônomo do Imperial Observatório. 
${ }^{3}$ O relatório elaborado por Silva Coutinho sobre a exploração do rio Purus data de 1862, mas foi incluído no relatório referente a 1864 apresentado à Assembleia Geral Legislativa pelo ministro e secretário de Estado dos Negócios da Agricultura, Comércio e Obras Públicas Jesuíno Marcondes de Oliveira e Sá, e publicado em 1865.

${ }^{4}$ Durante a exposição foi distribuído o livro O Império do Brazil na Exposição Universal de 1876 em Philadelphia, publicado em 1875 no Rio de Janeiro pela Tipografia Nacional, com 558 páginas, elaborado para apresentar as diversas facetas do Brasil, incluindo um capítulo sobre os museus de história natural, com ênfase ao Museu Nacional. Nele são destacadas como notáveis as coleções de geologia e mineralogia do museu.

${ }^{5}$ Foram duas viagens científicas, uma em 1870 e outra em 1871, assim batizadas em homenagem a Edwin Dennison Morgan (1811-1883), que contribuiu com expressivo valor para as expedições.

${ }^{6}$ Os fósseis foram posteriormente utilizados por Orville Derby na elaboração de sua tese para obter o grau de Master of Science e sua graduação de professor em 1874 na Universidade de Cornell, sendo publicada em seguida no periódico da instituição, Science, v.1, n.2, p.1-63, com o título "On the carboniferous Brachiopoda of Itaituba, rio Tapajós, prov. of Pará, Brazil" (Tosatto, 2001, p.5).

\section{REFERÊNCIAS}

AGASSIZ, Louis; AGASSIZ, Elisabeth Cary. Viagem ao Brasil: 1865-1866. Trad. João Etienne Filho. Belo Horizonte: Itatiaia: São Paulo: Edusp. 1975.

ALBUQUERQUE, Diogo Velho Cavalcanti de. Relatório apresentado à Assembleia Geral Legislativa na segunda sessão da décima quarta legislatura pelo Ministro e Secretário de Estado dos Negócios da Agricultura, Commercio e Obras Públicas Diogo Velho Cavalcanti de Albuquerque. Rio de Janeiro: Typographia Universal de Eduardo e Henrique Laemmert. 1870.

ALMANAK ...

Almanak administrativo, mercantil e industrial da Côrte e Província do Rio de Janeiro inclusive a cidade de Santos, da Província de São Paulo para o anno de 1876. Rio de Janeiro: Typographia Universal de Laemmert. 1876.

ALMANAK ...

Almanak administrativo, mercantil e industrial da Côrte e Província do Rio de janeiro para o anno de 1867. Rio de Janeiro: Typographia Universal de Laemmert. Disponível em: http://www.crl.edu/ brazil/almanak. Acesso em: 24 abr. 2013. 1867.

ALMANAK ...

Almanak administrativo, mercantil e industrial da Côrte e Província do Rio de Janeiro para o anno de 1865. Rio de Janeiro: Typographia Universal de Laemmert. Disponível em: http://www.crl.edu/ brazil/almanak. Acesso em: 24 abr. 2013. 1865.

ALMANAK ...

Almanak da Côrte e Província do Rio de Janeiro para o anno de 1864. Rio de Janeiro: Typographia Universal de Laemmert. Disponível em: http:// www.crl.edu/brazil/almanak. Acesso em: 24 abr. 2013. 1864a.

ALMANAK ...

Almanak administrativo mercantil e industrial da Côrte e Província do Rio de Janeiro para o anno de
1863. Rio de Janeiro: Typographia Universal de Laemmert. Disponível em: http://www.crl.edu/ brazil/almanak. Acesso em: 24 abr. 2013. 1863.

ALMANAK ...

Almanak administrativo mercantil e industrial da Côrte e Província do Rio de Janeiro para o anno de 1862. Rio de Janeiro: Typographia Universal de Laemmert. Disponível em: http://www.crl.edu/ brazil/almanak. Acesso em: 24 abr. 2013. 1862.

ALMANAK ...

Almanak administrativo mercantil e industrial da Côrte e Província do Rio de Janeiro para o anno de 1861. Rio de Janeiro: Typographia Universal de Laemmert. Disponível em: http://www.crl.edu/ brazil/almanak. Acesso em: 24 abr. 2013. 1861.

ALMANAK ...

Almanak administrativo mercantil e industrial da Côrte e Província do Rio de Janeiro para o anno de 1860. Rio de Janeiro: Typographia Universal de Laemmert. Disponível em: http://www.crl.edu/ brazil/almanak. Acesso em: 24 abr. 2013. 1860.

ALMANAK ...

Almanak administrativo mercantil e industrial da Côrte e Província do Rio de Janeiro para o anno de 1859. Rio de Janeiro: Typographia Universal de Laemmert. Disponível em: http://www.crl.edu/ brazil/almanak. Acesso em: 24 abr. 2013. 1859.

ALMANAK ...

Almanak militar para o anno de 1864. Col. 289, parte 1, fl. 28. (Arquivo Nacional, Rio de Janeiro). $1864 \mathrm{~b}$.

ALMEIDA, Thomaz José Coelho de.

Relatório apresentado à Assembleia Geral Legislativa na primeira sessão da décima sexta legislatura pelo Ministro e Secretário de Estado dos Negócios da Agricultura, Commercio e Obras Públicas Thomaz José Coelho de Almeida. Rio de Janeiro: Typographia Perseverança. 1877. 
AVISOS..

Avisos e Ofícios do Museu Nacional. Pasta 14, número 53, O389, DR CO AO 1754. (Setor de Memória e Arquivo do Museu Nacional, Rio de Janeiro). 5 out. 1875.

AVISOS...

Avisos e Ofícios do Museu Nacional. Documento pasta 14, número 27, O354, DR CO AO 1727. (Setor de Memória e Arquivo do Museu Nacional, Rio de Janeiro). 29 mai. 1875.

AVISOS...

Avisos e Ofícios do Museu Nacional. AO 1367, pasta 8a/201. (Setor de Memória e Arquivo do Museu Nacional, Rio de Janeiro). 11 nov. 1869.

AVISOS...

Avisos e Ofícios do Museu Nacional. AO 1315, pasta 8, doc. 145. (Setor de Memória e Arquivo do Museu Nacional, Rio de Janeiro). 31 ago. 1868.

AVISOS...

Avisos e Ofícios do Museu Nacional. AO 1124, pasta 7, doc. 136. (Setor de Memória e Arquivo do Museu Nacional, Rio de Janeiro). 24 nov. 1864.

BRAGA, Renato.

História da Comissão Científica de Exploração.

Mossoró: Coleção Mossoroense. Edição especial para o Acervo Virtual Oswaldo Lamartine de Faria. Disponível em: http:// www.colecaomossoroense.org.br/pics/historia dacomissao_cientifica_de_exploracao.pdf. Acesso em: 5 jan. 2011. 1982.

BRASIL GENEALÓGICO.

Brasil Genealógico, Rio de Janeiro, t.1, n.2. 1961.

BRICE, William R.; FIGUEIRÔA, Silvia F. de M. Charles Hartt, Louis Agassiz, and the controversy over Pleistocene glaciation in Brazil. History of Science, Cambridge, v.34, p.161-184. 2001.

CASTRO, Celso.

O espírito militar: um antropólogo na caserna. Rio de Janeiro: Jorge Zahar. 2004.

DEAN, Warren.

A luta pela borracha no Brasil: um estudo de história ecológica. Trad. Eduardo Brandão. São Paulo: Nobel. 1989.

DOCUMENTO...

[Documento referente à promoção do capitão João Martins da Silva Coutinho a major]. Fundo da Guerra do Paraguai. Arm. 2, v.3, fl. 75. (Arquivo Nacional, Rio de Janeiro). 1865.

DOUTOR JOÃO...

Doutor João Martins da Silva Coutinho. Revista do Club de Engenharia, Rio de Janeiro, n.14, p.VII-XII. 1906.

FERREIRA, Manuel Rodrigues.

A ferrovia do diabo. São Paulo: Melhoramentos. 2005.
FIGUEIRÔA, Silvia.

As ciências geológicas no Brasil: uma história social e institucional, 1875-1934. São Paulo: Hucitec. 1997.

FREITAS, Marcus Vinicius de.

Hartt: expedições pelo Brasil imperial, 1865-1878. São Paulo: Metalivros. 2001.

GROSS, Linda P.; SNYDER, Theresa R.

Philadelphia's 1876 Centennial Exhibition.

Charleston: Arcadia. 2005.

HARDMAN, Francisco Foot.

Trem-fantasma: a ferrovia Madeira-Mamoré e a modernidade na selva. São Paulo: Companhia das Letras. 1988.

HOLANDA, Bartolomeu Buarque de.

Buarque: uma família brasileira, ensaio históricogenealógico. Rio de Janeiro: Casa da Palavra. 2007.

INVENTÁRIO..

Inventário de João Martins da Silva Coutinho. Acervo Judiciário. Coleção Juízo de Órfãos e Ausentes da Segunda Vara. n.2007, cx.4238. Ano inicial: 1889. (Arquivo Nacional, Rio de Janeiro). 1889.

JORNAL...

Jornal do Commercio, Rio de Janeiro, 13 out. 1889.

JORNAL...

Jornal do Commercio, Rio de Janeiro, 12 out. 1889.

KODAMA, Kaori.

Em busca da gênese do Brasil nas províncias do Norte: Gonçalves Dias e os trabalhos etnográficos da Comissão Científica de Exploração. In: Kury, Lorelai (Org.). Comissão Científica do Império: 1859-1861. Rio de Janeiro: Andrea Jakobsson Estúdio. p.115-153. 2009.

KURY, Lorelai.

Comissão Científica do Império: 1859-1861. Rio de Janeiro: Andrea Jakobsson Estúdio. 2009a.

KURY, Lorelai.

Explorar o Brasil: o império, as ciências e a nação. In: Kury, Lorelai (Org.). Comissão Científica do Império: 1859-1861. Rio de Janeiro: Andrea Jakobsson Estúdio. p.19-49. 2009b.

LACERDA, João Baptista de.

Fastos do Museu Nacional do Rio de Janeiro: recordações históricas e científicas fundadas em documentos autênticos e informações verídicas. Rio de Janeiro: Imprensa Nacional. 1905.

LIVRO...

Livro de Entrada do Museu Nacional. D303, p. 225. (Setor de Memória e Arquivo do Museu Nacional, Rio de Janeiro). 7 mai. 1885. 
LIVRO...

Livro de Registro de Avisos e Ofícios. RA7/D7

(1875-1881), p.92v. (Setor de Memória e Arquivo do Museu Nacional, Rio de Janeiro). 6 set. 1878.

LIVRO...

Livro de Registro de Avisos e Ofícios. RA7/D7 (1875-1881), p.19v-20. (Setor de Memória e Arquivo do Museu Nacional, Rio de Janeiro). 18 abr. 1876.

LIVRO...

Livro de Registro de Avisos e Ofícios. RA7/D7 (1875-1881), p.17v. (Setor de Memória e Arquivo do Museu Nacional, Rio de Janeiro). 21 mar. 1876.

LIVRO...

Livro de Registro de Avisos e Ofícios. RA7/D7 (1875-1881), p.6-6v. (Setor de Memória e Arquivo do Museu Nacional, Rio de Janeiro).

15 out. 1875 .

LIVRO...

Livro de Registro de Avisos e Ofícios.RA6/

D6 (1869-1875), p.195v. (Setor de Memória e Arquivo do Museu Nacional, Rio de Janeiro). 29 mai. 1875.

LIVRO...

Livro de Registro de Avisos e Ofícios. RA6/D6 (1869-1875), p.110. (Setor de Memória e Arquivo do Museu Nacional, Rio de Janeiro).

30 nov. 1872.

LIVRO...

Livro de Registro de Avisos e Ofícios. RA6/D6 (1869-1875), p.46v-48. (Setor de Memória e Arquivo do Museu Nacional, Rio de Janeiro). 5 abr. 1871.

LIVRO...

Livro de Registro de Avisos e Ofícios. RA6/D6 (1869-1875), p.7-7v. (Setor de Memória e Arquivo do Museu Nacional, Rio de Janeiro).

29 nov. 1869.

LIVRO...

Livro de Registro de Avisos e Ofícios. RA6/D6 (1869-1875), p.6v. (Setor de Memória e Arquivo do Museu Nacional, Rio de Janeiro).

11 nov. 1869.

LIVRO...

Livro de Registro de Avisos e Ofícios. RA5/D5 (1861-1869), p.179. (Setor de Memória e Arquivo do Museu Nacional, Rio de Janeiro).

31 ago. 1868.

LIVRO...

Livro de Registro de Avisos e Ofícios. RA5/D5

(1861-1869), p.124. (Setor de Memória e Arquivo do Museu Nacional, Rio de Janeiro).

29 ago. 1866.
LIVRO...

Livro de Registro de Avisos e Ofícios. RA5/

D5 (1861-1869), p.119v. (Setor de Memória e Arquivo do Museu Nacional, Rio de Janeiro). 27 abr. 1866.

LOPES, Maria Margaret.

A Comissão Científica de Exploração: uma "expansão para dentro". In: Kury, Lorelai (Org.). Comissão Científica do Império: 1859-1861. Rio de Janeiro: Andrea Jakobsson Estúdio. p.51-83. 2009.

LOPES, Maria Margaret.

O Brasil descobre a pesquisa científica: os museus e as ciências naturais no século XIX. São Paulo: Hucitec. 1997.

LOPES, Maria Margaret.

Mais vale um jegue que me carregue, que um camelo que me derrube... Lá no Ceará. História, Ciências, Saúde - Manguinhos, Rio de Janeiro, v.3, n.1, p.50-64. 1996.

NETTO, Ladislau.

Investigações históricas e scientíficas sobre o Museu Imperial e Nacional do Rio de Janeiro. Rio de Janeiro: Instituto Philomatico. 1870.

PÁDUA, José Augusto.

Um sopro de destruição: pensamento político e crítica ambiental no Brasil escravista (17861888). Rio de Janeiro: Jorge Zahar. 2004.

PASTA...

[Pasta de documentos referente à carreira militar de João Martins da Silva Coutinho, extranumerário]. Pasta V 1344, CR n.241. (Arquivo Histórico do Exército, Rio de Janeiro). s.d.

ROSADO, Vingt-Un.

Silva Coutinho e a paleontologia de Mossoró.

Mossoró: Fundação Vingt-Un Rosado. (Coleção Mossoroense, Série C, n.1016). 1998.

ROSADO, Vingt-Un.

Dois nomes da história da paleontologia mossoroense. Mossoró: Fundação Vingt-Un Rosado. (Coleção Mossoroense. Série B, n.944). 1991.

SCHWARCZ, Lilia Moritz.

As barbas do imperador: D. Pedro II, um monarca nos trópicos. São Paulo: Companhia das Letras. 2006.

SILVA COUTINHO, João Martins da. Relatório apresentado ao conselheiro Antônio da Silva Prado sobre as estradas de ferro do Norte do Império. Mossoró: Fundação Vingt-Un Rosado. (Coleção Mossoroense, Série C, n.1017). 1998.

SILVA COUTINHO, João Martins da. Relatório da Commissão Brazileira apresentado 
ao Exm. Sr. Conselheiro Thomaz José Coelho de Almeida, Ministro e Secretário de Estado dos Negócios da Arquitetura, Comércio e Obras Públicas. Rio de Janeiro: Typografia Nacional. 1878.

SILVA COUTINHO, João Martins da. Officio dirigido ao Presidente da Provincia pelo engenheiro, logo depois de ter regressado do Purus. In: Oliveira e Sá, Jesuíno Marcondes de. Relatório apresentado à Assembleia Geral Legislativa na terceira sessão da décima segunda legislatura pelo Ministro e Secretário de Estado dos Negócios d'Agricultura, Commercio e Obras Públicas. Rio de Janeiro: Typographia Universal de Laemmert. p.A-O-1-A-O-96. 1865a.

SILVA COUTINHO, João Martins da. Relatório da Exploração do Rio Madeira pelo Doutor João Martins da Silva Coutinho. In: Oliveira e Sá, Jesuíno Marcondes de. Relatório apresentado à Assembleia Geral Legislativa na terceira sessão da décima segunda legislatura pelo Ministro e Secretário de Estado dos Negócios d'Agricultura, Commercio e Obras Públicas. Rio de Janeiro: Typographia Universal de Laemmert. p.A-Q-54-A-Q-63. 1865 b.
SILVA COUTINHO, João Martins da.

Relatório apresentado ao Illm. e Exm. Snr. Dr. Manoel Clementino Carneiro da Cunha, Presidente da Província do Amazonas, por João Martins da Silva Coutinho, encarregado de examinar alguns logares da província, especialmente o rio Madeira debaixo do ponto de vista da colonisação e navegação. Manaos: Typographia de F. J. da Silva Ramos. 1861.

TOSATTO, Pierluigi.

Orville A. Derby: o pai da geologia do Brasil. Rio de Janeiro: Companhia de Pesquisa e Recursos Minerais; Departamento Nacional da Produção Mineral. 2001.

VILLENEUVE, Julio Constancio de.

Relatorio sobre a Exposição Universal de 1867. Paris: Typographie Jules Claye. 1868.

VULTOS...

Vultos da geografia do Brasil: Silva Coutinho. Revista Brasileira de Geografia, Rio de Janeiro, v.4, n.3, p.574-575. 1942.

WHITE, Charles Abiathar.

Contribuições à paleontologia do Brasil. Archivos do Museu Nacional, Rio de Janeiro, v.7, p.1-273. 1887. 